\title{
Optimum Scheme for Insulation System in HV Generator based on Electromagnetic Analysis
}

\author{
D. Azizi \\ Dept of EE \\ IUST \\ Tehran, Iran \\ azizi@iust.ac.ir
}

\author{
A. Gholami \\ Dept of EE \\ IUST \\ Tehran, Iran
}

\begin{abstract}
Electrical insulations are one of the basic parts of electrical machinery in any sizes and characteristics. Focusing on insulating, studies on the operation of industrial-electrical machinery came to the fact that the most important part of a machine is the Stator. This fact reveals the requirement for inspection of the electrical machine insulation along with the electromagnetic tensions. Therefore with respect to insulation system improvement of stator, the HV generator can be optimized. Dielectric parameters such as insulation thickness, spacing, material types, geometry of winding and slot are major design consideration. A very powerful method available to analyze electromagnetic performance is Finite Element Method (FEM) which is used in this paper. The analysis of various stator coil and slot configurations are used to design the better dielectric system to reduce electrical stresses in order to increase the power of generator in the same volume of core. These processes of optimization have been done according the proposed algorithm. In this algorithm the technical constraints have been considered. This paper describes the process used to perform classical design and improvement analysis of stator slot's insulation with respect to objective function and constraints.
\end{abstract}

Keywords- insulation; FEM; machine; magnetic; thermal

\section{INTRODUCTION}

Safe operation of electrical machine, particularly high power generators strongly depends upon the health of stator coil insulation. Industrial researches show that troubles initiated in the stator winding insulation are one of the primary root causes of electric machine failures [1,2 and 3]. It is shown in $[4,5]$ that $30-40 \%$ of ac machine failures are stator related and also shown in [6] that $60-70 \%$ high voltage machine failures result from stator insulation troubles. The winding and core of stator integrity plays essential role in the reliability of the alternator [7-11]. Thus, performing the optimal design consist of electromagnetic study with respect to thermal limits in core, winding and insulation of stator slots is necessary. To attain an improved design electromagnetic analysis with observe to real condition is performed which completes pervious researches.

The reason of applying the method is investigating the effects of electrical, magnetically and thermal stresses on insulation parts. The main idea involves finding the optimum scheme of stator slot's insulation with respect to possible stresses and constraints. FEM analysis is used to simulate the electric, magnetic and thermal field simultaneously. The main supremacies of the simulations in comparison with other researchers are:

- Simulating ordinary rotation of rotor.

- Considering magnetic saturation of core.

- Considering of technical constraints.

According to this method, various configurations of stator (winding, core, slot, insulation) for operation conditions are proposed to investigate the possibility of improvement high voltage generator characteristics with respect to proposed optimization algorithm.

\section{ClassiCAL DESIGN}

M phase machine classical design has definite steps which are considered in this section. The induced KVA by armature can be obtained from:

$$
Q=m \cdot\left(\sqrt{2} \pi \cdot \mathrm{f} \cdot \varphi \cdot \mathrm{T}_{\mathrm{ph}} \cdot k_{w}\right) \cdot I_{p h} \cdot 10^{-3}
$$

Where:

$\varphi$ : total flux, $\mathrm{I}_{\mathrm{ph}}$ : phase current, $\mathrm{k}_{\mathrm{w}}$ : winding factor,

f: frequency, $T_{\text {ph }}$ : winding turn in phase

The equation (1) can be rewritten as (regarding to $f=\frac{p n_{s}}{2}, I_{z}=I_{p h}$ and $z=2 m T_{p h}$ )

$Q=\frac{\pi}{2 \sqrt{2}}(p \cdot \varphi)\left(\mathrm{I}_{\mathrm{z}} \cdot Z\right) n_{s} \cdot k_{w} \cdot 10^{-3}$

Total magnetic flux in air gape is called magnetic loading which is used to calculate especial magnetic loading $\left(\mathrm{B}_{\mathrm{av}}\right)$ as bellow:

Total magnetic loading $=\mathrm{p} \cdot \varphi$

$$
B_{a v}=p \varphi / \pi \mathrm{DL}
$$

Where:

D: diameter, L: length. 
Total current loading and especial current loading introduced by the following equations:

Total current loading $=I_{z} \cdot Z$

$a c=\frac{I_{z} Z}{\pi \mathrm{D}}$

By replacement and from equations (4) and (6) in equation (2), it can be shown that:

$$
\begin{gathered}
Q=\frac{\pi}{2 \sqrt{2}}\left(\pi \mathrm{DLB}_{\alpha \nu}\right)(\pi \mathrm{D} \alpha \mathrm{c}) \mathrm{n}_{\mathrm{s}} k_{w} \cdot 10^{-3}= \\
\left(1.11 \pi^{2} \mathrm{~B}_{\alpha \nu} \alpha \mathrm{ck}_{\mathrm{w}} \cdot 10^{-3}\right) D^{2} \operatorname{Ln}_{s}
\end{gathered}
$$

Where:

$$
C_{0}=1.11 \pi^{2} \mathrm{~B}_{\alpha \nu} \alpha \mathrm{ck}_{\mathrm{w}} \cdot 10^{-3}
$$

$\mathrm{k}_{\mathrm{W}}$ is winding factor which is calculated by multiplying $\mathrm{k}_{\mathrm{c}}$ and $k_{d} \cdot k_{c}$ is assumed one and $k_{d}$ is obtained from equation (9).

$$
k_{d}=\frac{\sin \frac{q a}{2}}{q \sin \frac{a}{2}}
$$

\section{CASE STUDY}

According to section 2, a generator with different insulation is designed as the case study. The selected generator is synchronous, three phase and two poles. Rated frequency, voltage and power are respectively $50 \mathrm{~Hz}, 20 \mathrm{KV}$ and $1 \mathrm{MVA}$. Wiring is form-wound multi-turn type and has many insulation layers with different specifications. In this study the turn insulation and the strand insulation are the same, i.e. nylon type. Ground wall insulation type is PTEF and semi conductive coating is $\mathrm{Si}(\mathrm{c})$ with characters identified in table 1.

TABLE I. ELECTRICAL AND THERMAL SPECIFICATIONS OF USED INSULATIONS

\begin{tabular}{|c|c|c|c|c|}
\hline Quantities & $\begin{array}{c}\text { Symbols \& } \\
\text { Dimensions }\end{array}$ & $\begin{array}{c}\text { Nylon } \\
\text { insulation }\end{array}$ & $\begin{array}{c}\text { PTEF } \\
\text { insulation }\end{array}$ & $\begin{array}{c}\text { Si(c) } \\
\text { insulation }\end{array}$ \\
\hline heat capacity & $\begin{array}{c}C \\
{\left[\mathrm{~J} /\left(\mathrm{kg}^{*} \mathrm{~K}\right)\right]}\end{array}$ & 1700 & 1420 & 700 \\
\hline $\begin{array}{c}\text { young's } \\
\text { modulus }\end{array}$ & $\begin{array}{c}E \\
{[\mathrm{~Pa}]}\end{array}$ & $2 \mathrm{e} 9$ & $3 \mathrm{e} 9$ & $170 \mathrm{e} 9$ \\
\hline $\begin{array}{c}\text { Thermal } \\
\text { expansion } \\
\text { coeff. }\end{array}$ & $\begin{array}{c}\mathrm{A} / \mathrm{K}] \\
\text { relative } \\
\text { permittivity }\end{array}$ & $280 \mathrm{e}-6$ & $70 \mathrm{e}-6$ & $2.6 \mathrm{e}-6$ \\
\hline $\begin{array}{c}\text { thermal } \\
\text { conductivity }\end{array}$ & $\begin{array}{c}\mathrm{K} \\
{\left[\mathrm{W} /\left(\mathrm{m}^{*} \mathrm{~K}\right)\right]}\end{array}$ & 0.26 & 0.19 & 130 \\
\hline density & $\begin{array}{c}\mathrm{Rho} \\
{\left[\mathrm{kg} / \mathrm{m}^{\wedge} 3\right]}\end{array}$ & 1150 & 1190 & 2329 \\
\hline
\end{tabular}

IV. ELECTROMAGNETIC MODELS [12]

Ampere's law is the main part to derive electromagnetic system equation. $\nabla \times H=J+\frac{\partial D}{\partial t}=\sigma E+\sigma v \times B+J^{e}+\frac{\partial D}{\partial t}$

Where:

- $E$ is the electric field intensity

- $\quad D$ is the electric displacement or electric flux density

- $H$ is the magnetic field intensity

- $B$ is the magnetic flux density

- $J$ is the current density

- $J^{e}$ is the externally generated current

- $\sigma$ is the electrical conductivity

- $v$ is the velocity

Time variant-harmonic field's effect can be introduced by equations (11) and (12):

$$
\begin{gathered}
B=\nabla \times A \\
E=-\nabla V-\frac{\partial A}{\partial t}
\end{gathered}
$$

Ampere's law is rewritten by equations (11) and (12) Combining with constitutive relationships $B=\mu_{0}(H+M)$ and $D=\varepsilon_{0} E+P$, as:

$$
\begin{aligned}
& \left(j \omega \sigma-\omega^{2} \varepsilon_{0}\right) A+\nabla \times\left(\mu_{0}^{-1} \nabla \times A-M\right) \\
& -\sigma v \times(\nabla \times A)+\left(\sigma+j \omega \varepsilon_{0}\right) \nabla V=J^{e}+j \omega P
\end{aligned}
$$

In which $\omega, \varepsilon_{0}, \mu_{0}, M$ and $P$ respectively refer to Angular frequency, Relative permittivity, Relative permeability, magnetization vector and electric polarization vector.

In the case of 2-dimensional-plane, there are no variations in z-direction, so the electric field is parallel to $z$-axis. , therefore $\nabla V$ is written as $-\Delta V / L$, where $\Delta V$ is the potential difference over the distance $L$. Now these equations are simplified to:

$$
\begin{aligned}
& -\nabla \cdot\left(\mu_{0}^{-1} \nabla A_{z}-\left[\begin{array}{c}
-M_{y} \\
M_{x}
\end{array}\right]+\sigma \cdot \nabla A_{z}+\left(j \omega \sigma-\omega^{2} \varepsilon_{0}\right)\right) A_{z} \\
& =\sigma \frac{\Delta V}{L}+J_{z}^{e}+j \omega P_{z}
\end{aligned}
$$

In the ax-symmetric case, another form of the electric potential gradient has been used $\left(\nabla V=\frac{-V_{\text {loop }}}{2 \pi \mathrm{r}}\right)$ as the electric field is only present in the azimuthally direction. The above equation, in cylindrical coordinates, becomes: 


$$
\begin{aligned}
& -\left([\partial / \partial r \partial / \partial z]\left(r \mu_{0}^{-1}\left[\begin{array}{l}
\partial u / \partial r \\
\partial u / \partial z
\end{array}\right]+\mu_{0}^{-1}\left[\begin{array}{l}
z \\
0
\end{array}\right] u-\left[\begin{array}{c}
M_{z} \\
-M_{r}
\end{array}\right]\right)\right) \\
& +r \sigma\left(v \cdot\left[\begin{array}{l}
\partial u / \partial r \\
\partial u / \partial z
\end{array}\right]\right)+r\left(\sigma j \omega-\omega^{2} \varepsilon_{0}\right) u+2 \sigma V_{r} u \\
& =\sigma \frac{V_{\text {loop }}}{2 \pi r}+J_{\varphi}^{e}+j \omega P
\end{aligned}
$$

The dependent variable $u$ is the nonzero component of the magnetic potential divided by the radial coordinate $r$, so that:

$$
u=A_{\varphi} / r
$$

The application mode performs this transformation to avoid singularities on the symmetry axis.

\section{OPTIMIZATION ALGORITHM}

The optimization procedure is presented in the optimization algorithm (Figure 1).

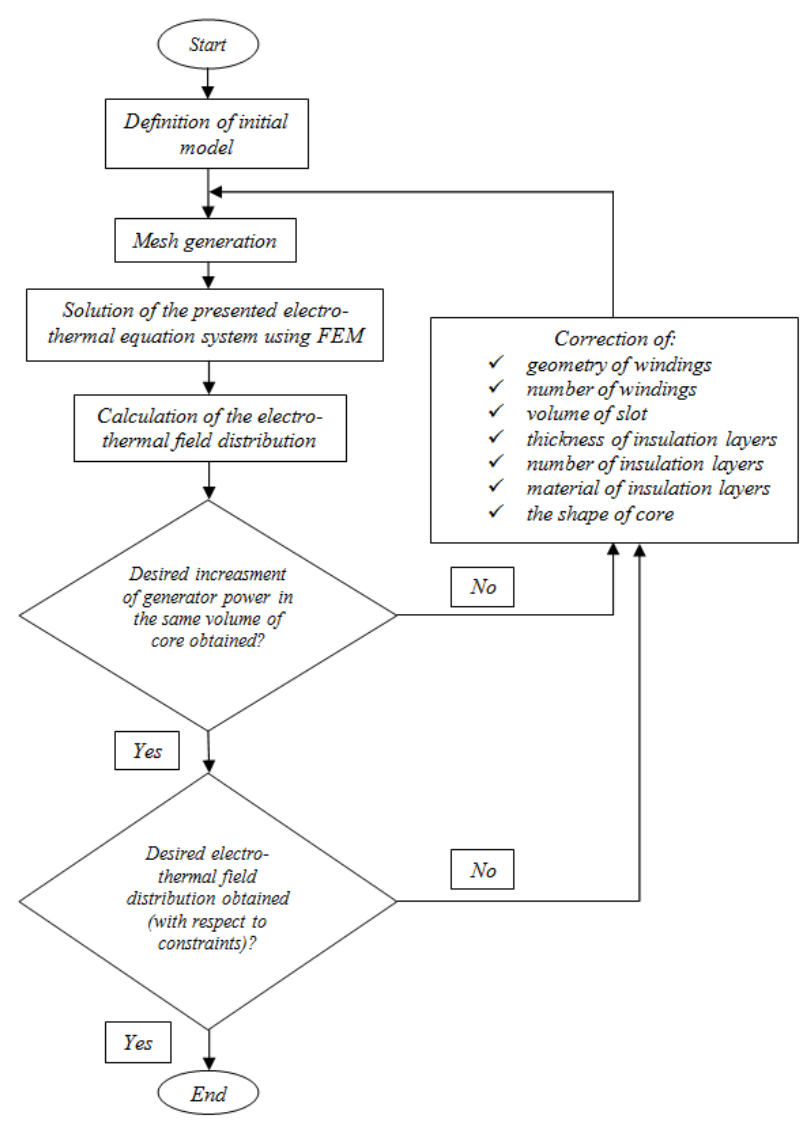

Fig. 3. Flow chart of the optimization procedure

\section{SIMULATION AND RESUlTS}

Following the development of the study, magnetic field distribution for cylindrical windings with two layers is simulated (Figure 2). Coupling the equations makes the capability of simulating electrical field and potential distribution as shown in (Figures 3,4). Varying configuration can include winding's geometry, slot depth, slot width, winding layers and material types of insulation. To study the effects of each varying on operation conditions some configurations are proposed. It should be mentioned that these changes of configuration are done according to optimization algorithm (Figure 1). In first step, cubic windings in the same cross section are used as Figure 5. The results of simulations show that electric field distribution has changed but the maximum electric field value is constant. The electric field distribution between winding layers has reduced intensively which allows adding a more layer (Figure 6). This means that the operation power can be enhanced $50 \%$. The length and depth of slots are two other options which impress design parameters. For this purpose, in the final step, the width of slot is increased. This is required the reduction of core volume which causes relatively core saturation (Figure 7).

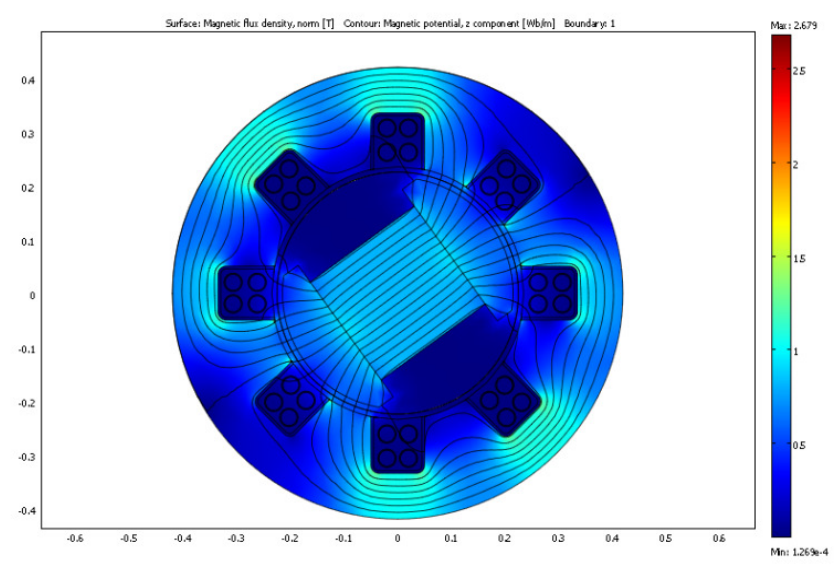

Fig. 4. Magnetic field distribution and flux lines

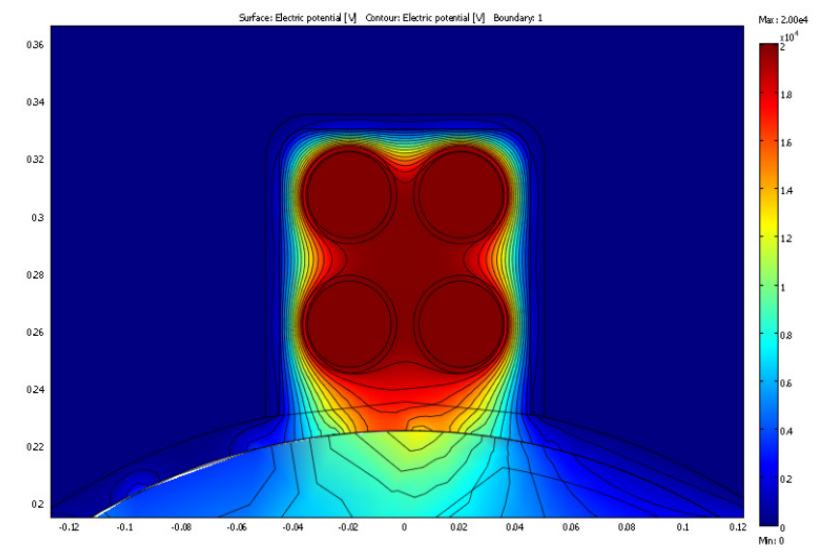

Fig. 5. Potential distribution in a sample slot 


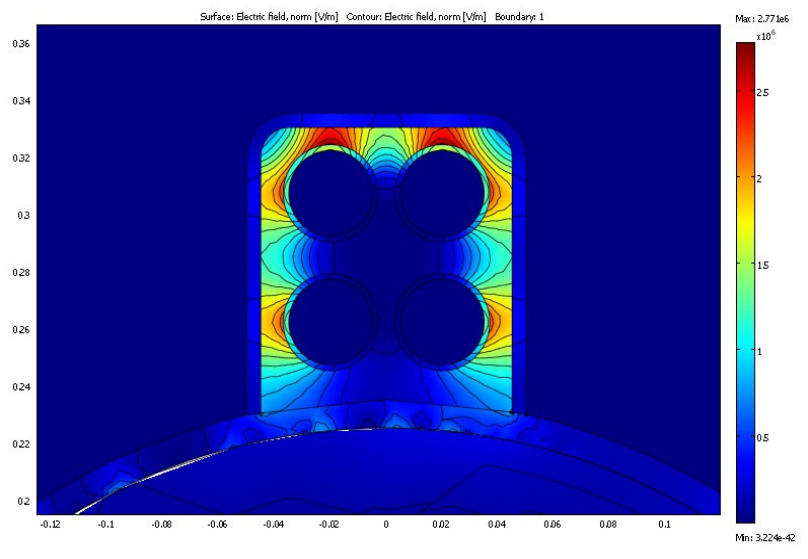

Fig. 6. Electrical field in a sample slot (mode 1)

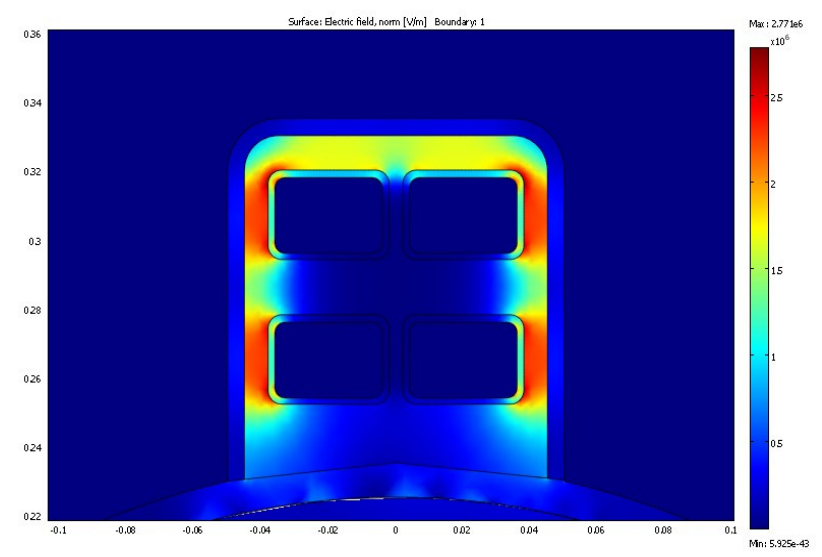

Fig. 7. Electrical field distribution for cubic winding (mode 2)

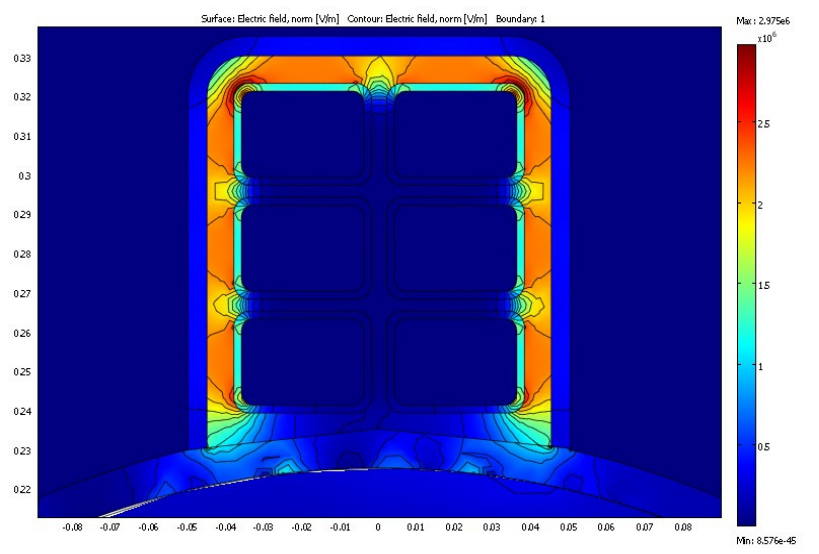

Fig. 8. Electrical field distribution for cubic windings with three layers (mode 3)

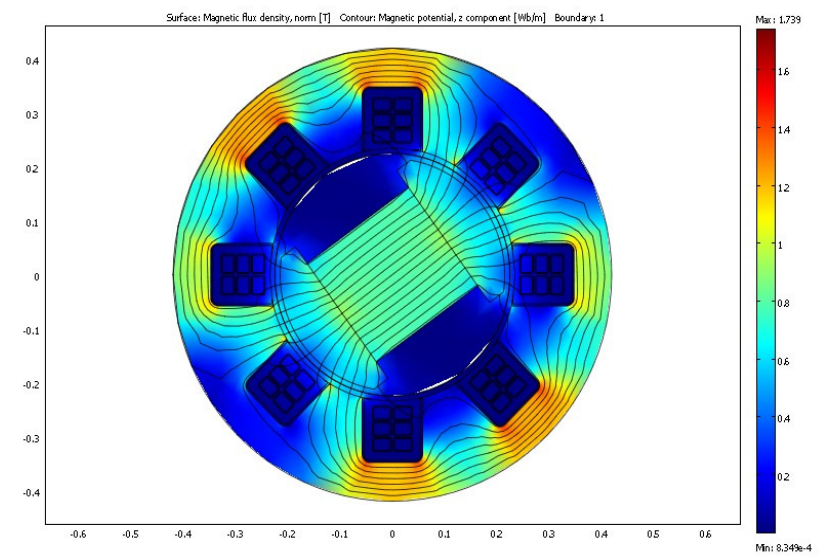

Fig. 9. Flux lines and magnetic distribution in generator with larger slot (mode 4)

TABLE II. MAXIMUM VALUES OF ELECTRICAL, MAGNETICAL AND THERMAL FIELDS IN ALL MODES

\begin{tabular}{|c|c|c|c|}
\hline & $\begin{array}{c}\text { Electrical field } \\
(\mathbf{k V} / \mathbf{m m})\end{array}$ & $\begin{array}{c}\text { Magnetic flux } \\
\text { density (T) }\end{array}$ & Temperature $\left({ }^{\circ} \mathbf{C}\right)$ \\
\hline Mode 1 & 2.77 & 1.5 & 78 \\
\hline Mode 2 & 2.77 & 1.5 & 79 \\
\hline Mode 3 & 2.97 & 1.5 & 87 \\
\hline Mode 4 & 1.86 & 1.73 & 112 \\
\hline
\end{tabular}

Comparing between varied configurations indicates that changing in the shape of winding geometry and insulation class are more effective. Thus, it can be claimed that the model of Figure 6 (mode 3 ) is the optimum configuration.

\section{CONCLUSION}

The majority of high voltage machine failures result from stator insulation problems. On the other hand electrical and magnetic stresses are the important factors of exhaustion in generators. Therefore selection of proper wiring scheme can decrease these stresses. Different schemes with regard to different construction have different characters and specification. The finite element electromagnetic and thermal analyses are useful to improve the configuration of stator which conquests the previous problems in classical design. In this paper, some proposed configurations presented and compared. It can be extracted from results that the configuration of Figure 6 is the optimum case with respect to mentioned algorithm.

\section{REFERENCES}

[1] F. T. Emery, D. Pavlik, "Electrostatic field analysis of high voltage generator stator insulation systems", IEEE Annual Report Conference on Electrical Insulation and Dielectric Phenomena, Vol. 2, pp. 510 - 513, 2000

[2] M. Arshad, A. Khaliq, S. M. Islam, "Turbo generator stator winding condition assessment", POWERCON International Conference on Power System Technology, Vol. 2, pp. 1399 - 1403, 2004. 
[3] S. B. Lee, J. Yang, K. Younsi, R. M. Bharadwaj, "An On-Line groundwall and phase to phase insulation quality assessment technique for AC-machine stator winding", IEEE Transactions on Industry Application, Vol. 42, No. 4, pp. 946-957, 2006.

[4] P. O'Donnell, "Report of large motor reliability survey of industrial and commercial installations: Part I", IEEE Transactions on Industry Application, Vol. IA-21, No. 4, pp. 853-864, 1985.

[5] "Report of large motor reliability survey of industrial and commercial installations: Part II", IEEE Transactions on Industry Application, Vol. IA-21, No. 4, pp. 865-872, 1985.

[6] P. F. Albrecht, J. C. Appiarius, D. K. Sharma, "Assessment of the reliability of motors in utility applications-Updated", IEEE Transactions on Energy Conversion, Vol. EC-1, No. 1, pp. 39-46, 1986.

[7] G. C. Montanari, M. Cacciari, "A probabilistic insulation life model for combined thermal-electrical stresses", IEEE Transactions on Electrical Insulation Vol. EI-20 No. 3, 1985.

[8] G. J. Anders, J. Endrenyi, G. L. Ford, G. C. Stone, "A probabilistic model for evaluating the remaining life of electrical insulation in rotating machines", lEEE Transactions on Energy Conversion, Vol. 5, No. 4, pp. $761-767,1990$.

[9] S. B. Pandey, "Estimation for a life model of transformer insulation under combined electrical and thermal stress", IEEE Transactions on Reliability, Vol. 41, No. 3, pp. 466 - 468, 1992.

[10] H. S. Endicott, B. D. Hatch, R. G. Sohmer, "Application of the eyring model to capacitor aging data", IEEE Transactions Component parts, Vol. 12, No. 1, pp. 34-41, 1965

[11] T. S. Ramu, "On the estimation of life power apparatus insulation under combined electrical and thermal stress," IEEE Transactions on Electrical Insulation, Vol. EI-20, pp. 70-78, 1985.

[12] D. Azizi, A. Gholami, A. Vahedi, "Analysis of the deterioration effects of stator insulation on the its electro-thermal property", International Journal of Electrical and Electronics Engineering, Vol. 3, No. 11, pp. 697- 701, 2009.

\section{AUTHORS PROFILE}
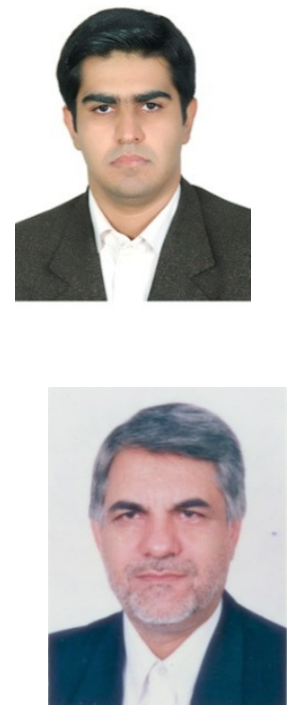

Diako Azizi was born in 1985. He has received B.Sc. degree in Electrical Engineering from Tabriz University, Tabriz, Iran in 2007. And he received the Master degree in Electrical Power Engineering from the University of Science and Technology, Tehran, Iran in 2009 . He is presently pursuing the Ph.D. degree in Electrical Power Engineering, Iran University of Science and Technology. His research interests are aging of insulations in electrical machines.

Ahmad Gholami has received his B.Sc. Degree in electrical engineering from IUST, Tehran, Iran, in 1975, the M.Sc. and PhD Degrees in electrical engineering from UMIST, Manchester, England, in 1986 and 1989 respectively. He is currently an associate professor in the Electrical Engineering Department of Iran University of Science and Technology. His main research activities are high voltage engineering, electrical insulation, insulation coordination, transmission lines and substations planning. 